Session 2457

\title{
Development of an Ergonomics and Safety Minor for Industrial and Manufacturing Curricula
}

\author{
Jorge Rodriguez, Tycho Fredericks \\ Human Performance Institute - Western Michigan University \\ Kalamazoo, MI 49008
}

\section{Introduction}

This paper presents the results of a pilot study undertaken to develop an Ergonomics and Safety Option for the Department of Industrial and Manufacturing Engineering (IME) at Western Michigan University (WMU). Due to the changes in legislation and work practice standards, there is a growing demand for engineers who have a thorough understanding of ergonomic and safety applications. To prepare industrial and manufacturing engineering students for today's work environment, courses should be geared toward developing a knowledge base to expand career opportunities and allow students the ability to move forward simultaneously with industrial advancements. The goal of this project was to research and develop an Ergonomic and Safety curriculum together with the definition of a standard curriculum design process that will allow for ease in future implementation of programs independent of the area of study. The basis of the defined procedure is a survey of involved parties. The outcome of the project included a course-specific Ergonomic and Safety curriculum. The proposed four-course/one-project minor implies the modification and creation of courses that cover the important learning objectives. Course contents and resource estimation are provided. This work was partially supported by the Society of Manufacturing Engineers-Education Foundation (SME-EF) ${ }^{1}$.

The high incidence of costly ${ }^{2,3}$ injuries and illnesses for employers may be a direct result of the mismatch between working conditions, human capacities, and job demands (ergonomics + safety). In order to better prepare students for today's work environment, it is necessary that Universities provide a dynamic curriculum which provides undergraduate students the knowledge, skills, and abilities to address the demands of industry. The study and field of industrial engineering is forefront in the movement toward ergonomic advancement within the workplace, yet according to Alexander, far too few industrial engineers retain ergonomics as one of their more commonly utilized tools ${ }^{4}$.

\section{Methodology}

A review of the systematic approach for curriculum development in Ergonomics and Safety area revealed limited information. Generally, curricular design could be grouped into three areas: laboratory design, course design, and program design. Articles on laboratory and course design focused on many of the same critical issues. This is not surprising in science oriented programs where many laboratories are treated as separate courses. The major issues revealed were a concentrated effort to move class instruction from a highly theoretical component (traditional engineering learning) to more of a hands on approach ${ }^{5,6,7}$, using technology as a supplemental instruction tool ${ }^{8}$, and catering delivery mechanisms for instruction around the individual 
student $^{9}$. Additionally, it is emphasized that when possible to make courses cross-disciplinary ${ }^{6}$. This type of approach lends itself well to integration of a variety of classes taken by students. Programmatically speaking there is a lack of "tradition" in teaching ergonomics and safety. Classically programs in ergonomics and/or safety reside in graduate programs in engineering, psychology, and occasionally computer science. The limited results of a literature search in this area may be due largely to the uniqueness of the topical area.

In order to define the specific needs in the Ergonomics and Safety curriculum, a methodology where a review of existing programs and the development of a list of commonalties was defined. In this methodology, once the common components were compiled, academicians and professionals in the field would rank the importance of the topics. The results of the rankings would lead to the formation of a taxonomy of educational components.

Existing Undergraduate Programs. According to the "Directory of Educational Programs in Ergonomics" published by the International Ergonomics Association (IEA) ${ }^{10}$, in terms of undergraduate education, most schools do not offer a degree in Ergonomics or Human Factors. In fact, among the universities listed, there is one engineering department that offers a bachelor degree in Human Factors (Wright State University, Human Factors Engineering), three psychology departments that offer bachelor degrees in Industrial Psychology (George Mason University, Purdue University, and Tufts University), and one institution that offers a bachelor degree in Human Factors through its department of Design and Environmental Analysis (Cornell University, College of Human Ecology). Of those schools which offer an "option", "minor", or "specialization" in Ergonomics (or Human Factors) at the bachelor degree level, only three were identified; two in engineering (Purdue University and Louisiana State University) and one in safety and systems management (University of Southern California).

Survey. A survey analysis was administered to industry to investigate, analyze, and compile information concerning the demand and requirements of ergonomic and safety concepts in the workplace. Results were compiled on the desired sample size, demographics of the survey population, demand industry places on knowledge of ergonomics and safety applications, as well as educational components industry felt were most applicable for new hires in the workforce. To determine the potential participants in the survey, it was decided to consider where the majority of WMU's Industrial Engineering (IE) students work after graduation, including type of industry and location. From a past survey completed by the College of Engineering and Applied Science $^{11}$, it was concluded that $64.9 \%$ of the graduating students with bachelors in engineering accepted starting positions in Michigan and a total of $73.3 \%$ started their careers in the Midwest. Based on these results, $60 \%$ of the questionnaires were sent to industries in Michigan, Illinois, Indiana, and Ohio. In the survey, statistics were also compiled on the type of employment students initially accept. Out of 154 bachelor students surveyed $88.3 \%$ were employed by business and industry. The remaining students had positions working in education, government, health and human services, or were attending graduate school. Due to the large number of students working in business and industry, the target population included employees from the similar fields. Prior to statistical analysis of the mass distribution survey it was necessary to determine if the sample size was sufficient. Of the 300 questionnaires that were mailed, it was found, with a confidence level of $99 \%$, that the sample size of 72 questionnaires exceeded the required sample size calculated for each question. 
The information gathered in the demographic portion of the questionnaire, showed that $51 \%$ of the respondents indicated their primary responsibilities are related to safety, $18 \%$ indicated that their primary responsibilities are related to ergonomics, $17 \%$ indicated that their primary responsibilities include both safety and ergonomic practices, and $14 \%$ were not able to be classified by the responses provided. The average experience in ergonomics and safety for the survey respondents was found to be 10.45 years. Sixty-eight percent of the industry employees had five or more years of experience in the fields of ergonomics and safety. The respondents were classified into categories based on their college education, including masters in ergonomics or safety; bachelors in industrial engineering, ergonomics or safety; bachelors in an engineering discipline; bachelors in a college program, or no bachelors degree. Participants were asked to rank their knowledge of ergonomics and safety into the following levels: inexperienced, somewhat experienced, experienced, advanced, and expert. The conclusions drawn from the demographic questions of the survey analysis indicate that the participants are primarily from industry and have adequate experience with the topics being investigated.

Validation of Demand. The second portion of the questionnaire contained five questions, which were written to serve as a validation tool for determining the demand for ergonomic and safety knowledge in the workplace. A ranking technique was used to classify the responses into the appropriate category. The following numbers were used to represent their answers: (1)-strongly disagree, (2)-disagree, (3)-somewhat disagree, (4)-somewhat agree, (5)-agree, and (6)-strongly agree. Statements were provided and the respondents were asked to agree or disagree on the given scale. The statements from these five questions are listed in Table 1, together with the average rating that was observed for each question.

Another question was also asked to determine if the respondent would take, or had taken, an ergonomic and safety program at the undergraduate level. The results indicated that $75 \%$ would enroll in the program or had already done so. Based on these results, it was concluded that both ergonomic and safety practices are considered important by industry, and a demand exists for these topics to be emphasized in an engineering curriculum.

Table 1 - Validation of Demand

\begin{tabular}{|l|c|l|}
\hline \multicolumn{1}{|c|}{ Statement } & Mean & \multicolumn{1}{|c|}{ Opinion } \\
\hline Ergonomics is important in your work environment. & 5.35 & Agree \\
\hline Safety is important in your work environment. & 5.70 & Strongly agree \\
\hline Ergonomic and safety awareness should be increased in your workplace. & 5.09 & Agree \\
\hline $\begin{array}{l}\text { Industrial engineering students who are educated in the application of } \\
\text { ergonomics and safety (E\&S) would be beneficial to your workplace. }\end{array}$ & 5.24 & Agree \\
\hline Education in E\&S applications would help you in your workplace. & 5.08 & Agree \\
\hline
\end{tabular}

Definition of Courses. The industry survey had a third section devoted to determining the educational components (learning objectives) that should be included in the curriculum. To determine the educational components, a list of ergonomics and safety learning objectives were presented to the participants who were asked to identify important topics from a list and rank their order of importance. Descriptive statistics of this analysis can be seen in Table 2. A higher mean value indicates an elevated level of importance. It was necessary to determine differences 
between mean responses of the educational components. Thus, a statistical analysis was performed on the educational components from the mass distribution survey. The process used to determine the importance of the educational components was very similar to Slowikowski ${ }^{12}$. The analysis included ranking of the educational components and determining if significant differences existed between the mean responses of the educational components. Based on this analysis, specific course contents for the ergonomics and safety curriculum were developed.

The Tukey method of multiple comparison was then used to make pairwise comparisons of the learning objective means. From the results of the Tukey statistical analysis, it was possible to determine the level of importance industry places on each of the educational components. The educational components were categorized as primary importance and secondary importance based on the significance level realized in the Tukey pairwise comparison. The sets for the ergonomic educational components were $\{\mathrm{E} 5, \mathrm{E} 8, \mathrm{E} 6, \mathrm{E} 7, \mathrm{E} 2, \mathrm{E} 9, \mathrm{E} 12\}$ and $\{\mathrm{E} 1, \mathrm{E} 3, \mathrm{E} 11, \mathrm{E} 4$, E10\}. Objective 13, "Reduce and Eliminate Ergonomic Stressors" was not selected as one of the top learning objectives by any of the respondents and was therefore eliminated from the data sets. The sets for the safety educational components were $\{\mathrm{S} 7, \mathrm{~S} 1, \mathrm{~S} 14, \mathrm{~S} 5, \mathrm{~S} 6, \mathrm{~S} 2, \mathrm{~S} 9\}$ and $\{$ S4, S8, S13, S10, S11, S3, S12). The educational component sets were used to formulate courses for the ergonomic and safety specialization. A greater emphasis was placed on those educational components deemed most important by industry because of the current distribution of students entering the work force in the Midwest.

Table 2. Ergonomics and Safety Educational Components

\begin{tabular}{|l|l|l|l|}
\hline MEAN & ERGONOMIC OBJECTIVES & MEAN & SAFETY OBJECTIVES \\
\hline 1.94 & E5 - Environmental Design & 1.87 & S7 - Personal Protective Equipment \\
\hline 1.93 & E8 - Implementing Ergo. Industry & 1.68 & S1 - Accident Investigation \\
\hline 1.85 & E6 - Equip. and Workplace Design & 1.61 & S14 - Workplace Hazards \\
\hline 1.80 & E7 - Human Machine Systems & 1.52 & S5 - Machine Safeguarding \\
\hline 1.63 & E2 - Cumulative Trauma Disorders & 1.48 & S6 - Occupational Injury Evaluation \\
\hline 1.17 & E9 - Occupational Biomechanics & 1.48 & S2 - Design for Health and Safety \\
\hline 1.06 & E12 - Workplace Physiology & 1.37 & S9 - Safety and Health Legislation \\
\hline 1.01 & E1 - Cognitive Ergonomics & 0.92 & S4 - Industrial Hygiene \\
\hline 0.90 & E3 - Engineering Anthopometry & 0.7 & S8 - Product Safety and Liability \\
\hline 0.70 & E11 - Survey Design & 0.59 & S13 - Worker Compensation \\
\hline 0.58 & E4 - Probabilities and Statistics & 0.52 & S10 - Stress and Safety \\
\hline 0.18 & E10 - Performance Modeling & 0.31 & S11 - Transportation Safety \\
\hline 0.00 & E13 - Reduce/Eliminate Stressors & 0.18 & S3 - Ethics and Safety \\
\hline & & 0.06 & S12 - Violence \\
\hline
\end{tabular}

The courses that will be either developed or modified are:

- Work Design [4 credits, revised - currently IME205], is the first course that must be taken in the ergonomics and safety minor. 
- Statistics and Probability for Engineers [3 credits each, revised - currently IME261/262], is a prerequisite for the proposed option.

- The Science of Ergonomics [4 credits, new]. This course will examine the methods for maximizing the health and safety of workers in an effort to maintain productivity and quality.

- Ergonomics and Design [4 credits, new]. The prerequisites for this class will be Work Design, Statistics and Probability for Engineers, and Engineering Economy. This course will investigate the human/machine relationship and interaction.

- Workplace Safety [3 credits, new]. A course to substitute for one of the industrial engineering electives.

- Ergonomic and Safety Capstone Project [2 credits, new]. The pinnacle of the ergonomic and safety minor involves this capstone course, which may be completed only after the requirements of the above courses have been fulfilled.

Proposed Implementation at WMU. Currently students enrolled in the industrial engineering curriculum at WMU must complete 129 credit hours to fulfill graduation requirements. Included in the 129 credit hours is a minor in mathematics, as well as two industrial engineering electives (6 credit hours). Upon implementation, the proposed 17-credit ergonomic and safety option will consist of four courses and a final ergonomic and safety capstone project. Work Design (IME 205) has been incorporated into the ergonomic and safety minor and is currently a required course for industrial engineering majors. Industrial and Manufacturing Engineering students will also be able to substitute the two industrial engineering electives with courses from the ergonomic and safety minor, thus lowering the number of additional credits that must be taken to complete the minor to seven.

\section{Project Justification}

Recruitment of Students. A student survey of the industrial engineering population at WMU provided a beneficial means by which to identify potential student enrollment in an ergonomic and safety curriculum. Statistical analysis of the student surveys was completed in an effort to forecast the number of students who would potentially enroll in an ergonomic and safety minor, if one were offered at WMU. A total of 40 student questionnaires were collected which was determined to be sufficient to reflect the views of the entire industrial engineering student population. The percentage of industrial engineering students surveyed by class level was determined to be $8 \%, 13 \%, 17 \%$, and $62 \%$, for freshmen, sophomores, juniors, and seniors, respectively. Note that the majority of students that responded were upperclassman. Our rationalization of having the higher upperclassmen populations was that the upperclassman have a better understanding of the current industrial engineering program.

Results of the survey showed that $40 \%$ of the students enrolled in the IE program are concurrently enrolled in a minor aside from the mathematics minor that is incorporated in the industrial engineering degree, $98 \%$ felt ergonomic and safety issues are prevalent in industry and indeed viable concerns in the workplace; $98 \%$ felt that a background in ergonomics and safety would be beneficial to industrial engineers in the workplace; $90 \%$ of the students indicated a willingness to take additional credits to earn a minor; $95 \%$ responded that a minor in ergonomics and safety would enhance their industrial engineering degree; and 70\% expressed their interest in 
earning a minor in ergonomics and safety in conjunction with their industrial engineering degree. Based from historical data obtained from the IME Department records, a regression analysis was utilized to forecast the trend in enrollment of industrial engineering students in the ergonomic and safety minor. Table 3 summarizes the student enrollment forecasting results for the years 2001 to 2005.

Resource Allocation. In order to justify the addition of an ergonomic and safety minor, it was necessary to determine the resources that are utilized in an ergonomic and safety laboratory to teach the design and science aspects of the program. This task was accomplished by conducting a Delphi survey of experts in the field of ergonomic and safety education and industrial application. A list of equipment, quantity recommended, quantity currently owned, and cost estimates for purchase and upkeep were provided. The Delphi respondents also indicated a recommended number of laboratory technicians and faculty that will be required to maintain and teach the ergonomic and safety minor. Calculations for the approximate cost of employees the necessary technicians and faculty were also provided.

Table 3 - Student Enrollment Forecast

\begin{tabular}{|c|c|c|c|}
\hline Year & $\begin{array}{c}\text { Forecasted } \\
\text { Enrollment }\end{array}$ & $\begin{array}{c}\text { Estimated } \\
\text { Cost/Credit }\end{array}$ & $\begin{array}{c}\text { Tuition } \\
\text { Revenues }\end{array}$ \\
\hline 2000 & 67 & $\$ 125$ & $\$ 29,334.11$ \\
2001 & 70 & $\$ 128$ & $\$ 31,558.39$ \\
2002 & 74 & $\$ 131$ & $\$ 33,859.92$ \\
2003 & 78 & $\$ 133$ & $\$ 36,240.88$ \\
2004 & 81 & $\$ 136$ & $\$ 38,703.53$ \\
\hline
\end{tabular}

After discussing the forecasted resource allocations with WMU, it was decided that the current resources available in the Human Performance Institute would be sufficient to serve an ergonomic and safety minor during its initial start-up. As the program gains recognition from regional industries and the University, grants and donations of money and equipment will also aid in funding the maintenance and equipment purchases.

\section{Conclusion}

The benefits for the students that take an Ergonomics and Safety minor are several. Among them it can be mentioned that graduating students will have the opportunity to take the Certified Safety Professional test. In addition, these students will be in a position to complete the first step towards earning a certification in ergonomics. In addition to becoming more marketable in industry, graduates will gain up-to-date knowledge of the ergonomic and safety trends in government legislation. This knowledge will better enable graduates to assist industry in complying with current and upcoming regulations. Finally, through completing the requirements for the ergonomic and safety minor, graduates will have gained critical exposure to industry, as well as research opportunities.

\section{Bibliography}

1. Society of Manufacturing Engineering grant \# 578-2501, "Conceptual Development of an Ergonomics/Human Factors Option, September 1998 - June 1999, J. Rodriguez and T.K. Fredericks (Principal Investigators). 
2. Bureau of Labor Statistics, 1999. Bureau of Labor Statistics Data. [On Line]. Available: http://bls.gov [1999, October].

3. OSHA web site. http://www.osha.gov (January 06, 2000).

4. Alexander, D. \& Pulat, B. (1985). Industrial ergonomics a practitioner's guide. Norcross: Industrial Engineering and Management Press.

5. Magliulo, T.W., Weins, K., Kimbell, S., Moody, L. (1997). An Ergonomics Workstation for the Undergraduate Human Factors Laboratory, Adavances in Occupational Ergonomics and Safety, Edited by B.Das and W. Karwowski, 333-336.

6. Greenstein, J. S. (1995). Introducing Human Centered Design Early in the Engineering Curriculum, Designing for the Global Village. Proceedings of the Human Factors and Ergonomics Society, Santa Monica, California, Volume 1, 389-393.

7. Soujourner, R.J., Olson, W.A., Serfoss, G.L. (1995). Performing the System Design Process: An Intelligent Way to Learn. Designing for the Global Village. Proceedings of the Human Factors and Ergonomics Society, Santa Monica, California, Volume 1, 221-236.

8. Hickox, J.C., Turner, S.L., Aretz, A.J. (1998) Enhancing Learning of Human Factors with Web-based Technology Applications, Proceedings of the $33^{\text {rd }}$ Annual Conference of the Human Factors and Ergonomics Society, Chicago, Illinois, 602-605.

9. Dekker, S., Rigner, J. (1999). Training for the Automated Task: Investigating Expertise for Modern Flight Decks, Engineering Psychology and Cognitive Ergonomics. Volume Three: Transportation systems, Medical Ergonomics and Training, Edited by D. Harris. Ashgate Publishing, Aldershot, Hampshire, 249-257.

10. International Ergonomics Association. http://www.iea.tut.fi (October 18,1998).

11. Western Michigan University Undergraduate Catalog, 1999-2001. http://www.wmich.edu (October 22, 1999).

12. Slowikowski, J. (1998). A Draft of a System of Teaching Occupational Safety and Ergonomics at Universities in Poland. International Journal of Occupational Safety and Ergonomics, 4(2), 221-236.

\section{JORGE RODRIGUEZ}

Jorge Rodriguez is an Assistant Professor in the Department of Industrial and Manufacturing Engineering and Research Associate of the Human Performance Institute at Western Michigan University. He received his Ph.D. in Mechanical Engineering from University of Wisconsin-Madison and received an M.B.A. from Rutgers University in Piscataway, NJ. Dr. Rodriguez teaches courses in Computer-Aided Design and Manufacturing, Mechanical Design, Biomechanics and Finite Element Analysis. His research is in the field of computers in engineering, with particular emphasis to machine design, foundry and biomechanics.

\section{TYCHO FREDERICKS}

Tycho Fredericks is an assistant professor in Department of Industrial and Manufacturing Engineering and codirector of the Human Performance Institute at Western Michigan University. He received his Ph.D. in Industrial and Manufacturing Engineering from Wichita State University in 1995 and is a member of the General Industry Safety Standards Commission for the state of Michigan. As an author of more than 35 referred publications, Dr. Fredericks maintains teaching and research interest in the areas of work-related musculoskeletal disorders and low back injuries. He is a member of the Human Factors Ergonomics Society, Institute of Industrial Engineers and is currently faculty advisor for the student chapter of the Institute of Industrial Engineers. 